\title{
Clinical Decision Making in Dermatology: Observation of Consultations and the Patients' Perspectives
}

\author{
F.M. Hajjaj ${ }^{a}$ M.S. Salek ${ }^{b}$ M.K.A. Basra ${ }^{a}$ A.Y. Finlay ${ }^{a}$ \\ ${ }^{a}$ Department of Dermatology and Wound Healing, School of Medicine, and ${ }^{b}$ Centre for Socioeconomic Research, \\ School of Pharmacy, Cardiff University, Cardiff, UK
}

\section{Key Words}

Decision making - Patients' perspectives - Management

decisions $\cdot$ Influences on decisions $\cdot$ Dermatology

\begin{abstract}
Background: Clinical decision making is a complex process and might be influenced by a wide range of clinical and nonclinical factors. Little is known about this process in dermatology. Aims: The aim of this study was to explore the different types of management decisions made in dermatology and to identify factors influencing those decisions from observation of consultations and interviews with the patients. Methods: 61 patient consultations were observed by a physician with experience in dermatology. The patients were interviewed immediately after each consultation. Consultations and interviews were audio recorded, transcribed and their content analysed using thematic content analysis. Results: The most common management decisions made during the consultations included: follow-up, carrying out laboratory investigation, starting new topical treatment, renewal of systemic treatment, renewal of topical treatment, discharging patients and starting new systemic treatment. Common influences on those decisions included: clinical factors such as ineffectiveness of previous therapy, adherence to prescribing guidelines, side-effects of medications,
\end{abstract}

previous experience with the treatment, deterioration or improvement in the skin condition, and chronicity of skin condition. Non-clinical factors included: patient's quality of life, patient's friends or relatives, patient's time commitment, travel or transportation difficulties, treatment-related costs, availability of consultant, and availability of treatment. Conclusion: The study has shown that patients are aware that management decisions in dermatology are influenced by a wide range of clinical and non-clinical factors. Education programmes should be developed to improve the quality of decision making.

Copyright $\odot 2010$ S. Karger AG, Basel

\section{Introduction}

Clinicians make a wide range of management decisions in routine clinical practice for their patients. Patient management decisions can be influenced by a number of orthodox clinical factors. For example, when a clinician encounters a patient with severe refractory psoriasis he or she is likely to resort to more aggressive systemic treatment (e.g. prescribing methotrexate) in order to control the patient's psoriasis. Similarly if a patient develops sideeffects from previous treatment (e.g. hypertension in a patient receiving cyclosporine), the clinician is inclined

\section{KARGER \\ Fax +4161306 1234 \\ E-Mail karger@karger.ch}

www.karger.com (c) 2010 S. Karger AG, Basel

$1018-8665 / 10 / 2214-0331 \$ 26.00 / 0$

Accessible online at:

www.karger.com/drm
Dr. Fadi M. Hajjaj

Department of Dermatology and Wound Healing

School of Medicine, Cardiff University, Heath Park

Cardiff CF14 4XN (UK)

Tel. +44292074 5876, Fax +44292074 4312, E-Mail fadihajjaj@hotmail.com 
to decrease the dose of this drug or to prescribe another treatment. Although in theory these decisions are primarily influenced by clinical factors, a wide range of what could be called 'non-clinical' factors may also influence their decision making [1-4]. Examples of non-clinical factors include: patient's socioeconomic status [3], physician and practice characteristics including physician's personal characteristics $[2,5,6]$, as well as influences of colleagues [7].

Our previous work has shown that dermatologists admit to a wide range of influences beyond diagnosis and severity on their clinical decision making [8]. For example, a patient's rude behaviour or being a complainer could influence the decision made by dermatologists. Similarly, clinic time constraints and the pressure of work in the clinic have been found to influence patient management to a certain degree and in a subconscious manner. Dermatologists have also reported that if patients speak poor English this would influence their management decisions [8].

Our previous work [8] gave an insight into clinicians' perspectives on the wide range of influences, beyond diagnosis and severity, which can impact on decision making. However, there is no information from the perspective of patients concerning the role of these influences. Understanding these influences would help in improving this important aspect of clinical practice and in the development of teaching strategies and integration of this knowledge into practice guidelines.

The aim of this study was to explore various clinical and non-clinical influences on management decisions in dermatology from the observation of consultations and perspectives of patients.

\section{Methods}

The study was approved by the South East Wales Local Research Ethics Committee and all participants gave written informed consent before the observed consultations and the interviews. The study consisted of observation of consultations and then patient interviews immediately after the consultation. The study took place in the general dermatology outpatient clinics at the University Hospital of Wales, Cardiff. Patients were selected according to the time of their clinic appointment with at least a 1-hour gap between each consultation. Patients were sent an invitation letter, information sheet and consent form 1 week prior to their appointments. During the consultations, the observer recorded all management decisions as well as his understanding and inferences of the factors that were thought to influence these decisions. Immediately after the consultations, the patients were interviewed to further explore observations made during the consultations as well as to seek the patients' views on the factors in-
Table 1. Demographic characteristics of the 61 study patients

\begin{tabular}{lc}
\hline Patients & Number \\
\hline Males & $25(41 \%)$ \\
Females & $36(59 \%)$ \\
Caucasians & $58(95 \%)$ \\
Non-Caucasians & $3(5 \%)$ \\
Employed & $27(44 \%)$ \\
Retired & $23(38 \%)$ \\
Students & $6(10 \%)$ \\
Unemployed & $5(8 \%)$ \\
\hline
\end{tabular}

fluencing their management decisions. An interview prompt sheet was used during the interviews. The consultations and interviews were audio recorded when permission was granted by the clinician and patient.

Interviews and consultations were transcribed verbatim and analysed manually using thematic content analysis. The process of thematic content analysis involves analysing transcripts of observations and interviews, identifying themes within those data and gathering together examples of those themes [9]. This involves discovering themes in the observation and interview transcripts and attempting to verify, confirm and qualify them by searching through the data and repeating the process to identify further categories [9]. The researcher reads each transcript and makes notes in the margin of words, sentences or paragraphs (open coding). The notes provide a summary statement or words for each element that is discussed in the transcript. Explanation is derived through moving back and forth between analysis and data, continually comparing one respondent's view with another's in order to confirm the emergent theme [9]. The researcher then collects all summary statements or words onto a clean set of pages. All duplications are crossed out and overlapping or similar categories are refined and reduced in number by grouping them together. A final list of categories is produced supported by quotations from the participants [9].

A final list of factors influencing patient management decisions was made supported by quotations from consultations and patients. The list was reviewed and approved by the research team. In addition, influences from consultations and interviews were also presented separately.

\section{Results}

\section{Demographics of the Study Participants}

Eighty-nine patients were invited to participate in this study. Nine (10\%) declined to take part, 8 (9\%) cancelled their appointments, and 11 (12\%) did not attend. Consequently, 61 patients $(68.5 \%)$ were recruited into the study (table 1$)$. The patients' mean age was 47.8 years $(\mathrm{SD}=18.7$, median $=45.5$, range $=18-87)$. Forty-one $(67 \%)$ were follow-up patients and $20(33 \%)$ were new patients. 
The patients were under the care of 17 different clinicians; consultants $(n=5)$, specialist registrars $(n=3)$, specialist nurses $(n=3)$, senior house officers $(n=3)$, and clinical lecturers $(n=3)$. All interviews were audio recorded. However, permission was given by both clinician and patient for audio recording in only 36 (59\%) consultations.

The study was approved by the South East Wales Local Research Ethics committee. All participants consented to take part prior to the study commencement.

The patients had a wide variety of skin diseases $(\mathrm{n}=$ 23). Psoriasis, acne and atopic eczema were the most common conditions. The mean duration of skin diseases was 11.5 years $(S D=15$, range $0.3-66)$. Selected quotations from the consultations and patient interviews are presented in the Appendix.

\section{Management Decisions}

During the 61 consultations, a total of 163 management decisions were made, later grouped into 17 different categories (table 2). The mean number of management decisions taken per patient was 2.7 (range $=1-6$ ). The most common management decisions $(\mathrm{a}-\mathrm{g})$ are listed below.

(a) Follow-up: 49 follow-up decisions were made during the 61 consultations (table 2). The most common influence on follow-up decisions was the clinician's adherence to prescribing guidelines: for example, a decision to follow up a patient on isotretinoin treatment or a decision to follow-up a patient who had a melanoma removed.

(b) Order laboratory investigations: A total of 28 decisions to order laboratory investigations were made (table 2). The most common influence on this decision was the clinician's adherence to prescribing guidelines: for example, ordering a pregnancy test for a female patient on isotretinoin.

(c) The decision to start a new topical treatment: 16 decisions to start patients on a new topical treatment were made. The most common influences on these decisions included: ineffectiveness of previous therapy $(n=8)$, deterioration of quality of life $(n=6)$, deterioration in the skin condition $(n=5)$, and side-effects of the previous medication $(\mathrm{n}=4)$.

(d) Renewal of a systemic treatment: 14 decisions to renew a systemic treatment were made: for example, the re-prescription of isotretinoin to a patient with acne and who was already on this treatment. The most common influences on these decisions were clinician adherence to prescribing guidelines $(\mathrm{n}=12)$ and ineffectiveness of previous therapy $(\mathrm{n}=9)$ (table 2$)$. (e) Renewal of a topical treatment: 12 decisions to renew a topical treatment were made: for example, the represcription of a calcipotriol ointment to a patient with psoriasis. The most common influences on these decisions included deterioration in the skin condition $(\mathrm{n}=7)$ and chronicity of skin lesion $(\mathrm{n}=4)($ table 2$)$.

(f) Discharge patients to the referring physician: 12 discharge decisions were made: for example, discharging a patient with mild psoriasis to the referring general practitioner. The most common influences on these decisions were patients presenting with benign skin lesions $(n=7)$ and skin condition improved to a level that the patient can be managed by the general practitioner $(\mathrm{n}=2)(\mathrm{ta}-$ ble 2).

(g) Start new systemic treatment: 11 decisions to start the patient on a new systemic treatment were made: for example, prescribing methotrexate to a patient with deteriorating psoriasis. The most common influences on these decisions were: ineffectiveness of previous therapy $(\mathrm{n}=9)$, deterioration in the skin condition $(\mathrm{n}=7)$ and impairment in the patient's quality of life $(\mathrm{n}=7)$ (table 2).

\section{Factors Influencing Patient Management Decisions}

Factors influencing patient management decisions, identified from consultations and patient interviews, with explanations, are given in table 3 .

\section{Factors Influencing Patient Management Decisions}

Identified during the Consultations

A total of 150 influences were identified by the observer during the consultations ( mean $=2.5$, range $=1-8$ ). Nineteen consultations had one influential factor, 18 consultations had two, 13 consultations had three, five consultations had four, two consultations had five, three consultations had six, and one consultation had eight influential factors. Influential factors during the consultations were categorized into 21 themes and are listed according to their frequencies in table 4 .

\section{Factors Influencing Patient Management Decisions} Identified during the Interviews

A total of 129 influences on patient management decisions were identified during the patient interviews (mean $=2.1$, range $=1-5)$. Twenty-six interviews identified one influential factor, 16 interviews two, nine interviews three, six interviews four, and four interviews identified five influential factors. Influential factors during the interviews were categorized into 15 themes and are listed according to their frequencies in table 5. 
Table 2. Management decisions made during consultations and their influential factors $(\mathrm{n}=61)$

\begin{tabular}{ll}
\hline Decisions & $\begin{array}{l}\text { Total number of } \\
\text { influences associated } \\
\text { with each decision }\end{array}$ \\
\hline
\end{tabular}

Follow-up $(\mathrm{n}=49)$

Prescribing guidelines $(\mathrm{n}=21)$

Deterioration in the skin condition $(n=7)$

Improvement in the skin condition $(\mathrm{n}=7)$

Patient's quality of life $(\mathrm{n}=4)$

Patient's preferences and wishes $(\mathrm{n}=3)$

Side-effects of medication $(\mathrm{n}=2)$

Patient's time commitment $(\mathrm{n}=2)$

Malignant nature of the lesion $(n=2)$

Unavailability of the consultant $(\mathrm{n}=2)$

Chronicity of the skin lesion $(n=1)$

Clinician's perceived patient's non-adherence $(n=1)$

Ineffectiveness of previous therapy $(n=1)$

Friends and relatives $(\mathrm{n}=1)$

Laboratory investigations

$(\mathrm{n}=28)$

Prescribing guidelines $(\mathrm{n}=23)$

Clinician's uncertainties $(n=2)$

Advice from a senior clinician $(\mathrm{n}=2)$

Side-effects of medication $(n=1)$

Deterioration in the skin condition $(n=1)$

Starting new topical treatment 30

$(\mathrm{n}=16)$

30

(n)

Ineffectiveness of previous therapy $(\mathrm{n}=8)$

Patient's quality of life $(n=6)$
Deterioration in the skin condition $(n=5)$

Side-effects of medication $(n=4)$

Patient's time commitment $(\mathrm{n}=2)$

Advice from a senior clinician $(\mathrm{n}=1)$

Improvement in the skin condition $(\mathrm{n}=1)$

Patient's preferences and wishes $(\mathrm{n}=1)$

Clinician's perceived patient's non-adherence $(\mathrm{n}=1)$

Previous experience with the treatment $(n=1)$

Renewal of systemic treatment $\quad 41$

$(\mathrm{n}=14)$

41

Prescribing guidelines $(n=12)$

Ineffectiveness of previous therapy $(n=9)$

Friends and relatives $(\mathrm{n}=4)$

Patient's quality of life $(\mathrm{n}=4)$

Patient's preferences and wishes $(n=3)$

Improvement in the skin condition $(\mathrm{n}=3)$

Side-effects of medication $(\mathrm{n}=2)$

Chronicity of the skin lesion $(\mathrm{n}=2)$

Advice from a senior clinician $(\mathrm{n}=1)$

Patient's time commitment $(\mathrm{n}=1)$

Renewal of topical treatment 19

$(\mathrm{n}=12)$

19

Deterioration in the skin condition $(n=7)$

Chronicity of the skin lesion $(\mathrm{n}=4)$

Improvement in the skin condition $(\mathrm{n}=2)$

Side-effects of medication $(n=2)$

Patient's quality of life $(n=1)$

Patient's preferences and wishes $(\mathrm{n}=1)$

Patient's time commitment $(\mathrm{n}=1)$

Clinician's uncertainties $(\mathrm{n}=1)$

Discharge $(\mathrm{n}=12)$

13

Benign nature of the lesion $(n=7)$

Improvement in the skin condition $(\mathrm{n}=2)$

Chronicity of the skin lesion $(n=2)$

Patient's quality of life $(\mathrm{n}=1)$

Advice from a senior clinician $(n=1)$ 
Table 2 (continued)

\begin{tabular}{|c|c|c|}
\hline Decisions & $\begin{array}{l}\text { Total number of } \\
\text { influences associated } \\
\text { with each decision }\end{array}$ & Types of influences on each decision \\
\hline $\begin{array}{l}\text { Starting new systemic } \\
\text { treatment }(\mathrm{n}=11)\end{array}$ & 34 & $\begin{array}{l}\text { Ineffectiveness of previous therapy }(\mathrm{n}=9) \\
\text { Deterioration in the skin condition }(\mathrm{n}=7) \\
\text { Patient's quality of life }(\mathrm{n}=7) \\
\text { Friends and relatives }(\mathrm{n}=2) \\
\text { Scientific journals }(\mathrm{n}=2) \\
\text { Side-effects of medication }(\mathrm{n}=2) \\
\text { Advice from a senior clinician }(\mathrm{n}=1) \\
\text { Patient's preferences and wishes }(\mathrm{n}=1) \\
\text { Chronicity of the skin lesion }(\mathrm{n}=1) \\
\text { Travel or transportation difficulties }(\mathrm{n}=1) \\
\text { Treatment-related costs }(\mathrm{n}=1)\end{array}$ \\
\hline Day care treatment $(\mathrm{n}=4)$ & 11 & $\begin{array}{l}\text { Deterioration in the skin condition }(n=3) \\
\text { Patient's quality of life }(n=2) \\
\text { Ineffectiveness of previous therapy }(n=1) \\
\text { Patient's preferences and wishes }(n=1) \\
\text { Previous experience }(n=1) \\
\text { Clinician's uncertainties }(n=1) \\
\text { Unavailability of consultant }(n=1) \\
\text { Clinician's perceived patient's non-adherence }(n=1)\end{array}$ \\
\hline Photography $(\mathrm{n}=4)$ & 4 & $\begin{array}{l}\text { Malignant nature of skin lesion }(\mathrm{n}=1) \\
\text { Benign nature of skin lesion }(\mathrm{n}=1) \\
\text { Advice from a senior clinician }(\mathrm{n}=1) \\
\text { Deterioration in the skin condition }(\mathrm{n}=1)\end{array}$ \\
\hline Surgical excision $(\mathrm{n}=3)$ & 5 & $\begin{array}{l}\text { Malignant nature of skin lesion }(\mathrm{n}=2) \\
\text { Patient's quality of life }(\mathrm{n}=1) \\
\text { Friends and relatives }(\mathrm{n}=1) \\
\text { Patient's concerns }(\mathrm{n}=1)\end{array}$ \\
\hline Referral $(\mathrm{n}=2)$ & 4 & $\begin{array}{l}\text { Unavailability of treatment }(\mathrm{n}=2) \\
\text { Patient preferences and wishes }(\mathrm{n}=2)\end{array}$ \\
\hline UV therapy $(\mathrm{n}=2)$ & 8 & $\begin{array}{l}\text { Deterioration in the skin condition }(n=2) \\
\text { Patient's quality of life }(n=2) \\
\text { Ineffectiveness of previous therapy }(n=2) \\
\text { Patient's preferences and wishes }(n=1) \\
\text { Previous experience }(n=1)\end{array}$ \\
\hline $\begin{array}{l}\text { Decreasing the dose of systemic } \\
\text { treatment }(n=2)\end{array}$ & 2 & Side-effects of medication $(\mathrm{n}=2)$ \\
\hline $\begin{array}{l}\text { Increasing the dose of systemic } \\
\text { treatment }(n=1)\end{array}$ & 2 & $\begin{array}{l}\text { Ineffectiveness of previous dose }(n=1) \\
\text { Deterioration in the skin condition }(n=1)\end{array}$ \\
\hline $\begin{array}{l}\text { Intralesional steroid injection } \\
(\mathrm{n}=1)\end{array}$ & 4 & $\begin{array}{l}\text { Ineffectiveness of previous therapy }(\mathrm{n}=1) \\
\text { Patient's preferences and wishes }(\mathrm{n}=1) \\
\text { Chronicity of the skin lesion }(\mathrm{n}=1) \\
\text { Previous experience }(\mathrm{n}=1)\end{array}$ \\
\hline Cryotherapy $(\mathrm{n}=1)$ & 4 & $\begin{array}{l}\text { Patient's quality of life }(n=1) \\
\text { Patient's preferences and wishes }(n=1) \\
\text { Chronicity of the skin lesion }(n=1) \\
\text { Previous experience }(n=1)\end{array}$ \\
\hline $\begin{array}{l}\text { Stopping the systemic treatment } \\
(\mathrm{n}=1)\end{array}$ & 1 & Improvement in the skin condition $(\mathrm{n}=1)$ \\
\hline
\end{tabular}


Table 3. Influences on patient management decisions identified from the consultations and patients' interviews

1 Ineffectiveness or failure of previous therapy or dose, for example, starting a systemic treatment when topical treatment fails to control psoriasis

2 Clinician's adherence to prescribing guidelines, for example, ordering a pregnancy test for a female patient on isotretinion

3 Patient's quality of life, for example, taking more aggressive management decision, e.g. prescribing cyclosporin in a female patient with prurigo nodularis because the disease is very embarrassing for her (Appendix, quotation 1)

4 Deterioration of the skin condition, for example, starting methotrexate or day care treatment in a patient with deteriorating psoriasis

5 Improvement in the skin condition, for example, discharging patient to primary care when the skin condition improves

6 Side-effect of medications, for example, patient declines dapsone treatment because of its side-effect profile (Appendix, quotation 2)

7 Patient's wishes and preferences, for example, patient prefers one treatment over another (e.g. preference of creams over ointments because ointments are sticky)

8 Relatives and friends, for example, a patient's friend recommending treatment with isotretinoin or methotrexate (Appendix, quotation 3)

9 Chronicity of skin condition, for example, when the skin disease is of a chronic nature with periods of exacerbation and remission with no available curative treatment, then the physician may be left with a limited number of options to offer to the patient, e.g. discharging patients or repeating the same treatment (Appendix, quotation 4)

10 Patient's time commitment at work, school or with family, for example, patient may decline UV treatment because it interferes with work commitment.

11 Previous experience with a treatment; patient may opt for a treatment that was effective in the past (Appendix, quotation 5)
12 Advice from senior clinician; clinicians with little experience in dermatology may seek advice from the consultants or other senior clinicians about patients' management decisions, for example, advice from senior clinician to carry out certain laboratory investigations

13 Clinician's uncertainties about diagnosis or management, for example, physician may order blood tests when he or she is uncertain about the cause of generalized itching

14 Travel or transportation difficulties, for example, patient may decline day care treatment because he or she lives far away from hospital (Appendix, quotation 6)

15 Treatment-related costs, for example, cost of time off work and cost of parking

16 Availability of consultant, for example, a junior clinician did not take any treatment or investigative decisions and gave the patient a follow up appointment because the consultant was not present in the clinic

17 Influence of scientific journal, for example, clinician quoting and prescribing a treatment based on a published article

18 Malignant nature of the lesion, for example, booking the patient for surgical excision when the lesion looks malignant, e.g. a patient with basal cell carcinoma

19 Availability of treatment, for example, referring a patient with acne to a private clinic for cosmetic treatment

20 Clinician's perceived patient non-adherence, for example, when the patient is old and lives alone the clinician might advise the patient to come for day care treatment to ensure patient compliance

21 Benign nature of skin lesion, for example, discharging patient with benign lesions such as seborrhoeic keratosis

22 Patient's concerns, for example, removal of benign lipoma because the patient is concerned about it being malignant (Appendix, quotation 7)

\section{Influences Identified during the Consultations versus} Influences Identified during the Interviews

Some influences were identified during the consultations but not during the patient interviews. These are: (a) clinician's adherence to clinical guidelines; (b) clinician seeking advice from senior clinicians about patient management; (c) clinician's uncertainties about diagnosis and management; (d) the unavailability of a consultant during the clinic timing; (e) the influence of a scientific journal on selecting a particular treatment; (f) the unavailability of a specific treatment in the clin- ic; (g) clinician's perceived patient's non-adherence to treatment.

We identified only one influential factor during the interview which had not been observed during the consultation. A male patient with multiple lipomatosis was worried about the condition being a form of cancer: this influenced his decision to have these lesions removed surgically.

There were influential factors common between the consultations and the interviews but with different frequencies. These are listed in table 6. Noticeably, there 
Table 4. Influences on patients' management decisions identified during the consultations

\begin{tabular}{lll}
\hline Influential factors on patient management decisions & $\begin{array}{l}\text { Frequency of } \\
\text { influential factor }\end{array}$ \\
\hline & & 25 \\
2 & Clinician adherence to clinical guidelines & 17 \\
3 & Deterioration in the skin condition & 16 \\
4 & Feterioration in patient quality of life & 15 \\
5 & Improvement in the skin condition & 13 \\
6 & Side-effects of medications & 10 \\
7 & Chronicity of skin disease & 9 \\
8 & Patient preferences and wishes & 8 \\
9 & Benign nature of the lesion or skin condition & 7 \\
10 & Clinician seeking advice from a senior clinician about patient management & 6 \\
11 & Patient time commitment at work, school or with family & 6 \\
12 & Clinician's uncertainties about diagnosis and management & 4 \\
13 & Patient's previous experience with treatment & 3 \\
14 & Malignant nature of the skin lesion & 2 \\
15 & The influence of a scientific journal on selecting a particular treatment & 2 \\
16 & Unavailability of consultant during the clinic & 2 \\
17 & Unavailability of a specific treatment in clinic & 1 \\
18 & Influence of family members and friends on patient management & 1 \\
19 & Travel or transportation difficulties & 1 \\
20 & Financial status of the patient and treatment-related costs & 1 \\
21 & Clinician's perceived patient non-adherence to treatment & 1 \\
\hline & & \\
\hline
\end{tabular}

Table 5. Influences on patient management decisions identified during the interviews

\begin{tabular}{rlr}
\hline Influential factors on patient management decisions & $\begin{array}{l}\text { Frequency of } \\
\text { influential factor }\end{array}$ \\
\hline & & 30 \\
2 & Deterioration in the patient's quality of life & 22 \\
3 & Failure of previous treatment or dose to improve the skin condition & 11 \\
4 & Improvement in the skin condition & 10 \\
5 & Influence of family members and friends on patient management & 10 \\
6 & Chronicity of skin disease & 9 \\
7 & Patient's time commitment at work, school or with family & 8 \\
8 & Deterioration in the skin condition & 7 \\
9 & Patient's previous experience with treatment & 6 \\
10 & Benign nature of the lesion or skin condition & 6 \\
11 & Patient's preferences and wishes & 4 \\
12 & Travel or transportation difficulties & 2 \\
13 & Financial status of the patient and treatment-related costs & 2 \\
14 & Malignant nature of the skin lesion & 1 \\
15 & Patient's concern and worries & 1 \\
\hline
\end{tabular}

were influences which were far more commonly identified during the interviews than during the consultations. For example, the influence of a patient's family members and friends was prominent during the interviews and the influence of the patient's quality of life was twice as com- mon during the interviews than during the consultations, and the influence of the patient's previous experience with the treatment was also more commonly identified during the interviews (table 6). 
Table 6. Comparison of common influential factors identified during the consultations and the interviews and their frequencies

\begin{tabular}{lll}
\hline Influential factors on patient management decisions & $\begin{array}{l}\text { Frequency of } \\
\text { influential factor } \\
\text { during the } \\
\text { consultations }\end{array}$ & $\begin{array}{l}\text { Frequency of } \\
\text { influential factor } \\
\text { during the } \\
\text { interviews }\end{array}$ \\
\hline Deterioration in the skin condition & 17 & 7 \\
Patient's quality of life & 16 & 30 \\
Failure of previous treatment or dose to improve the skin & 15 & 22 \\
$\quad$ condition & 13 & 10 \\
Improvement in the skin condition & 10 & 11 \\
Side-effects of medications & 9 & 9 \\
Chronicity of skin disease & 8 & 4 \\
Patient's preferences and wishes & 7 & 6 \\
Benign nature of the lesion or skin condition & 6 & 8 \\
Patient's time commitment at work, school or with family & 3 & 6 \\
Patient's previous experience with treatment & 2 & 1 \\
Malignant nature of the skin lesion & 1 & 2 \\
Influence of family members or friends on patient management & 1 & 2 \\
Travel or transportation difficulties & 1 & \\
Financial status of the patient and treatment-related costs & & \\
\hline
\end{tabular}

On the other hand, there were influences which were more commonly identified during the consultations, for example, deterioration in the skin condition and the patient's preferences and wishes for specific treatment. Other influences had only slight differences in their frequency of identification between the consultations and interviews (table 6).

\section{Analysis of Individual Management Decisions and Their Influential Factors}

One management decision can be influenced by one or by more than one influential factor as shown in table 2 . For example, a woman with deteriorating psoriasis in whom previous treatments had failed to control her psoriasis and whose psoriasis impacted on her daily activities preferred more aggressive treatment. The decision to start UVB in this patient was influenced by all three factors. Another example is starting a new systemic treatment such as isotretinoin in a patient with acne, which may be influenced by factors such as ineffectiveness of previous topical treatments, deterioration of the skin condition, impairment in the patient's quality of life, and opinion of friends and relatives who may have had similar treatment (table 2).

\section{Discussion}

This study has shown that the decision-making process in dermatology is influenced by a wide range of clinical and non-clinical factors. In addition, it has documented the types of management decisions made during the consultations in the dermatology outpatient clinics. Some of the influences identified in this study, such as the side-effects of medications and clinician's adherence to prescribing guidelines, are examples of clinical influences. On the other hand, the patient's quality of life, treatment-related costs, travel difficulties, patient time commitment, influence of friends and relatives and the patient's concerns and worries are examples of non-clinical influences.

It is self-evident that clinicians are already aware of many of the clinical influences identified in this study. However, non-clinical influences, beyond diagnosis and severity, are not usually discussed by clinicians and might influence the decision-making process in a subconscious manner [8]. For example, our study showed that deterioration in a patient's quality of life influenced important decisions such as initiating systemic treatments, e.g. methotrexate in psoriasis, for patients who failed on topical treatments. Our study identified the influence of the patient's quality of life twice as often during the patient interviews than during the consultations. This highlights 
the importance for clinicians of taking into consideration assessment of the patient's quality of life when making management decisions. This may not happen due to time constraints on the clinic [8]. In fact, David et al. [10] found that quality of life discussion was absent in $40 \%$ of routine general dermatology consultations.

Another interesting finding is that the influence of the patient's family members or friends was far more prominent during the interviews than during the consultations. Perhaps by the time of the interviews, patients had had sufficient time to think about their previous experiences with medications and about who had influenced their choice of treatment. Family members of patients with skin diseases sometimes play an important role in the management decisions concerning their relatives, as shown in our study. For example, they may provide necessary information during the consultation that the patient forgot to tell, they may have experienced similar illness or treatment in the past, they may help in applying ointments, or they may be available to drive the patient back and forth to hospital, thus facilitating certain treatment options such as UV therapy or day care [8]. Family members may feel encouraged to help because skin diseases can affect not only the quality of life of patients but also the quality of life of their family members, a social group that has been called 'the Greater Patient' $[11,12]$.

Some influences were found to be more commonly identified during the consultations than during the interviews: for example, the influence of a patient's preferences for a specific treatment. This might be because patients usually voice their preferences at the time of decision making with the treating clinician, which is during the consultations. Another example is the influence of deterioration of skin condition on patient management, which was identified more commonly during the consultations. This might be because of the subjective inferences from the observer about the severity of skin diseases which were more obviously assessable during the consultations. In addition, patients may not have wished to repeat their view of their disease severity twice, during the consultations and during the interviews.

Our study has also shown that the patient's socioeconomic circumstances, such as place of residence and availability of transportation to the hospital, influence some management decisions which require regular attendance, such as starting UVB treatment. Different management options are considered for patients who live far away from hospital compared with patients who live near the hospital or have easy access to transportation. Patients' time commitment may also impact on their man- agement [8]. Patients who go to school or university may not wish to jeopardize their study by attending, for example, day care treatment [8]. Acne patients in the lower socio-economic groups were less likely to visit a dermatologist for specialist consultation [13] due to financial limitations. Other non-clinical influences on the lack of attendance at secondary-care clinics include socio-economic barriers such as further time off work [14], being busy with children at home [15], treatment costs and difficulty in transportation to the clinic [16-19].

One important issue which we did not explore in this study is the influence of clinicians' personal characteristics as well as their attitudes and prejudices towards some patients. Every clinician has a unique personality which may impact his or her decision making. For example, female physicians were more likely than males to be influenced by the patient's context and social factors when making management decisions [20], and they spend more time with patients $[21,22]$. Female clinicians were less likely to withdraw life-sustaining treatment in patients with terminal cancer than male physicians [6]. In addition, the race of a clinician may influence patient management. For example, African-American physicians tend to desire more aggressive treatment than Caucasians at end-of-life situations because of the influence of their spiritual beliefs [5]. There is also a prejudiced attitude among some Caucasian physicians who are less willing to interact with members of minority groups than nonCaucasian physicians [23]. Physicians may believe that patients from an ethnic minority are less likely to comply with treatment [23]. For example, Bogart et al. [24] found that physicians predicted that African-American men would be less likely to receive highly active anti-retroviral treatment for HIV infection because they would be less likely to adhere to treatment. In one UK study [25], psychiatrists were asked to read and diagnose a case history describing an agitated patient with paranoid delusions whose family reported that they suspected the patient had been smoking cannabis. The authors found that Afro-Caribbean patients were more likely to be diagnosed as having cannabis psychosis while white patients were more likely to be diagnosed as having schizophrenia; this highlighted a prejudiced attitude amongst physicians toward black patients, considering them more likely to show antisocial or criminal behaviour.

Physician attitudes toward homosexual colleagues or patients may influence their decision making. For example, in one study in 1986 in the USA, 39.4\% of physicians stated that they were often uncomfortable in dealing with homosexual patients [26]. In the same study, more that 
$40 \%$ of physicians stated that they would stop referring patients if they learned that a colleague to whom they previously referred patients was a homosexual.

These prejudiced influences on physician decision making are not unique to the field of medicine. For example, in the legal world, particularly in underdeveloped countries, there may be a strong influence from political parties on the decision making of judges which may involve corruption and intimidation [27]. Judges in the United States usually respond to political pressure in an effort to be re-elected or re-appointed [28]. In addition, the characteristics of the victim and the offender may influence the decisions of judges [29, 30]. In a study [29], if the victim was an important person in society, for example an entrepreneur, the judge tended to sentence the offender to a greater number of years in prison than if the victim was from a low social class or a former offender. In addition, Steffensmeier et al. [30] found that young black male offenders are usually sentenced more harshly than any other group.

\section{The Concept of 'Good' and 'Bad' Non-Clinical Influences}

Non-clinical influences identified in this study can be considered as either good or bad influences on decision making in dermatology. 'Bad' or inappropriate influences, such as patient's place of residence, can encourage clinicians to consider, for example in patients with psoriasis, systemic potentially toxic treatment rather than day care or UV therapy. Another potentially 'bad' influence is treatment-related costs resulting in patients receiving inferior treatment. It is, however, appropriate, when making management decisions, to take into consideration certain 'good' or appropriate non-clinical influences, such as patient's adherence, quality of life, and concerns and worries. Encouraging such 'good' influences on decision making could strengthen the doctorpatient relationship, increase the patient's confidence in the doctor and enhance his or her adherence to treatment.

\section{Study Limitations}

Although this study has highlighted certain important aspects of clinical decision making, it also has several limitations. While all patient interviews were audio recorded, 25 consultations were not, due to lack of permission from patients or clinician. Important information might have been missed during the observation of unrecorded consultations. Although the observer (F.M.H.) is a physician with experience in dermatology, we did not verify his observations during the consultations with the respective clinicians. This was because we opted for a non-participatory role for the observer, and because of the time constraints in the clinic. Another study that explores clinicians' views on factors influencing their clinical decision making in dermatology is reported separately [8].

\section{Conclusion}

This study has shown the diversity of management decisions and the complexity of the decision-making process in dermatology and described aspects of the reality of decision making beyond the conventional evidence-based model. Management decisions in dermatology are influenced by a wide range of clinical and nonclinical factors. Knowledge about this area, especially the non-clinical influences, is often unacknowledged and untaught. If clinicians were made more aware of such issues in their decision making, this might improve the quality of decision making and hence treatment outcomes. Teaching about factors influencing clinical decision making in dermatology should be included in the curricula of medical schools as well as in the postgraduate education of physicians and other healthcare practitioners.

\section{Appendix}

Quotation 1: Patient's quality of life

Patient: 'I think I decided to go for tablets, you know, because it is very embarrassing you sit on and ...' [patient acted as if scratching]. (A female patient with prurigo nodularis.)

Quotation 2: Side-effects of medications

Patient: 'I knew that the gluten-free diet would take a little while for it to work, but I did pick up information on dapsone and the side-effects to me didn't sound that good.' (A male patient with dermatitis herpetiformis.)

Quotation 3: Influence of friends or relatives

Patient: 'A friend recommended tablets ... a friend recommended trying methotrexate ... I didn't realize that she has been on tablets for quite a long time and she said: "you should have asked for these tablets”.' (A female patient with psoriasis.)

Quotation 4: Chronicity of skin disease

Clinician: 'As I explained, there is no cure for this condition, that is why we can carry on injections every 3 months.' (A quotation from a consultation with a male patient with acne keloidalis nuchae.) 
Quotation 5: Previous experience with the treatment

Patient: 'The ultraviolet treatment was brilliant in the past.' Clinician: 'Would you like to consider some more of the light treatment?' Patient: 'yes'. (A quotation from a consultation with a female patient with psoriasis.)

\section{Quotation 6: Travel or transportation difficulties}

Patient: 'It is getting me down now, takes three days a week ... catching a bus to the station ... a bus from the station up here ... Sometimes I ache and pain because I suffer from my lesions on my back.' (A female patient with psoriasis.)

\section{Quotation 7: Patient's worries and concerns}

Patient: 'A lot of friends ... whoever knows about it ... they suggest yeah you should go and get something done about it, you know, probably before it gets bigger ... tumour or something ... somebody did scare me by saying something like that ...' (A male patient with lipomatosis.)

\section{Acknowledgment}

The study was funded by the Quality of Life Research Fund, Department of Dermatology and Wound Healing, Cardiff University. We wish to thank the patients for their contribution and for giving permission for their quotes to be published and the clinicians who allowed F.M.H. to observe consultations in their clinics.

\section{Disclosure Statement}

There is no direct or indirect financial implication that publication of this paper may have for the authors, their relatives, or their institution.

\section{References}

1 Eisenberg JM: Sociologic influences on decision making by clinicians. Ann Intern Med 1979;90:957-964

2 McKinley JB, Potter DA, Feldman HA: Nonmedical influences on medical decision making. Soc Sci Med 1996;42:769-776.

- 3 Bernheim SM, Ross JS, Krumholz HM, Bradley EH: Influence of patients' socioeconomic status on clinical management decisions: a qualitative study. Ann Fam Med 2008;6:53-59.

4 Hajjaj FM, Salek MS, Basra MK, Finlay AY: Non-clinical influences on clinical decision making: a major challenge to evidence based practice. J R Soc Med 2010;103:178-187.

5 Modi SC, Whetstone LM, Cummings DM: Influence of patient and physician characteristics on percutaneous endoscopic gastrostomy tube decision-making. J Palliat Med 2007;10:359-366.

-6 Hinkka H, Kosunen E, Metsanoja R, Lammi U-K, Kellokumpu-Lehtinen P: Factors affecting physicians' decisions to forgo lifesustaining treatments in terminal care. J Med Ethics 2002;28:109-114.

7 Feely J, Chan R, McManus J, O'Shea B: The influence of hospital-based prescribers on prescribing in general practice. Pharmacoeconomics 1999; 16:175-181.

8 Hajjaj FM, Salek MS, Basra MK, Finlay AY: Non-clinical influences, beyond diagnosis and severity, on clinical decision making in dermatology: understanding the gap between guidelines and practice. $\mathrm{Br} J$ Dermatol 2010;163:789-799.

-9 Burnard P, Gill P, Stewart E, Treasure E, Chadwick B: Analysing and presenting qualitative data. Br Dent J 2008;204:429-432.

10 David SE, Ahmed Z, Salek MS, Finlay AY: Does enough quality of life-related discussion occur during dermatology outpatient consultations? Br J Dermatol 2005;153:997-1000.
Basra MK, Finlay AY: The family impact of skin diseases: the Greater Patient concept. $\mathrm{Br}$ J Dermatol 2007;156:929-937.

12 Eghlileb AM, Davies EE, Finlay AY: Psoriasis has a major secondary impact on lives of family members and partners. Br J Dermatol 2007;156:1245-1250.

13 Haider A, Mamdani M, Shaw JC, Alter DA, Shear NH: Socioeconomic status influences care of patients with acne in Ontario, Canada. J Am Acad Dermatol 2006;54:331-335.

14 Cohen AD, Dreiher J, Vardy DA, Weitzman $D$ : Non-attendance in a dermatology clinic: a large sample analysis. J Eur Acad Dermatol Venereol 2008;22:1178-1183.

15 York R, Williams P, Munro BH: Maternal factors that influence inadequate prenatal care. Public Health Nurs 2007;10:241-244.

16 Sable MR, Libbus MK, Chiu JE: Factors affecting contraceptive use in women seeking pregnancy tests: Missouri, 1997. Fam Plann Perspect 2000;32:124-131.

17 Ahmed SM, Lemkau JP, Nealeigh N, Mann $B$ : Barriers to healthcare access in non-elderly urban poor American population. Health Soc Care Community 2001;9:445-453.

18 Fitzpatrick AL, Powe NR, Cooper LS, Ives DJ, Robbins JA: Barriers to healthcare access among the elderly and who perceive them. Am J Public Health 2004;94:1788-1794.

19 Ramchandani SR, Mehta SH, Saple DG, Vaidya SB, Pandey VP, Vadrevu R, Rajasekaran S, Bhatia V, Chowdhary A, Bollinger RC, Gupta A: Knowledge, attitude, and practices of antiretroviral therapy among HIVinfected adults attending private and public clinics in India. AIDS Patient Care STDS 2007;21:129-142.
20 Tracy CS, Dantas GC, Moineddin R, Upshur RE: Contextual factors in clinical decision making: national survey of Canadian family physicians. Can Fam Physician 2005; 51:1106-1107.

21 Bensing JM, van den Brink-Muinen A, de Bakker DH: Gender differences in practice style: a Dutch study of general practitioners. Med Care 1993;31:219-229.

22 Franks P, Bertakis KD: Physician gender, patient gender, and primary care. J Womens Health 2003;12:73-80.

23 Balsa AI, McGuire TG: Prejudice, clinical uncertainty and stereotyping as sources of health disparities. J Health Econ 2003;22:89-116.

24 Bogart LM, Kelly JA, Catz SL, Sosman JM: Impact of medical and nonmedical factors on physician decision making for HIV/AIDS antiretroviral treatment. J Acquir Immune Defic Syndr 2000;23:396-404.

25 Lewis G, Croft-Jeffreys C, David A: Are British psychiatrists racist? Br J Psychiatry 1990; 157:410-415.

26 Mathews WM, Booth MW, Turner JD, Kessler L: Physicians' attitude toward homosexuality - Survey of a California Country Medical Society. West J Med 1986;144:106-110.

27 Glaeser E, Scheinkman J, Shleifer A: The injustice of inequality. J Monet Econ 2003;50: 199-222.

28 Shepherd JM: The influence of retention politics on judges' voting. J Legal Stud 2009;38: 169-203.

29 Landy D, Aronson E: The influence of character of criminal and his victim on the decisions of simulated jurors. J Exp Soc Psychol 1969;5:141-152.

30 Steffensmeier D, Ulmer J, Kramer J: The interaction of race, gender, and age in criminal sentencing: the punishment cost of being young, black and male. Criminology 1998; 36:763-798. 